\title{
An investigation into the changing relationship between the gold price and South African gold mining industry returns
}

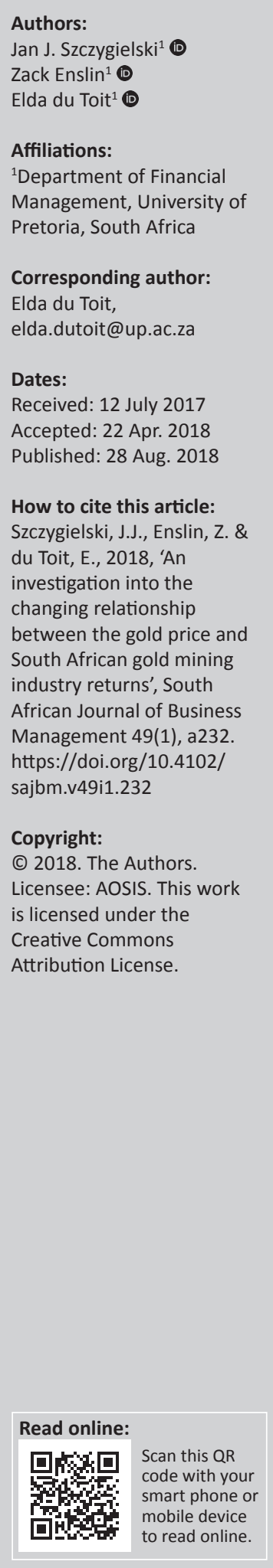

Background: It is accepted that the gold price impacts on the value of gold mining companies. Previous studies have shown that, in financial crises, gold is considered a 'safe haven' investment in developed markets.

Aim: The aim of the study is to investigate whether an investment in gold mining stocks do provide gold price-linked safe haven benefits to investors in an emerging economy. An understanding of the possible safe haven benefits of their companies' stocks and the variables that influence these benefits would be valuable to managers of gold companies when endeavouring to maximise shareholders' wealth through hedging and investment decisions.

Methods: Regression analysis is applied to investigate the relationship between gold mining returns, the gold price and the rand-dollar exchange rate within a multifactor model motivated by the arbitrage pricing theory.

Results: The results indicate that there is a strong, yet changing, relationship between the gold price, the rand-dollar exchange rate and gold mining returns.

Conclusion: This study extends the understanding of the changing South African gold mining industry in a world that is still recovering from the global financial crisis.

\section{Introduction}

Baur and McDermott (2010:1887) state that 'the beauty of gold is, it loves bad news'. In times of uncertainty, gold is an attractive investment option. Even though there is no theoretical model to explain the 'safe haven' effect of gold (Baur \& Lucey 2010), Gil-Alana, Aye and Gupta (2015), McCown and Zimmerman (2006) and Shafiee and Topal (2010) still suggest that gold is a valuable diversification tool as it provides returns that are uncorrelated with financial markets and has inflation hedging characteristics. Various previous international studies investigated whether investment in gold mining stocks provides similar investment benefits to investment in gold itself (Faff \& Hillier 2004; Fang, Lin \& Poon 2007; Gilmore et al. 2009; Tufano 1998). The global financial crisis provides fertile ground for an investigation of the possible safe haven effect of investment in gold (Baur \& Lucey 2010; Baur \& McDermott 2010; Fei \& Adibe 2010; Shafiee \& Topal 2010). This should be extended to investigate whether an investment in gold mining stocks provided gold price-linked safe haven benefits to investors. An understanding of the possible safe haven benefits of their companies' stocks and the variables that influence these benefits would be valuable to managers of gold companies when endeavouring to maximise shareholders' wealth through hedging and investment decisions.

This study addresses this issue by investigating the impact of the US dollar-based gold price movements on the value of the Johannesburg Stock Exchange (JSE) Gold Mining Index (code: J150), an index comprising South African gold mining company stocks, as well as the US dollar-South African rand exchange rate. This is done by estimating a multifactor model implied under the arbitrage pricing theory (APT), which relates returns on the Gold Mining Index to fluctuations in the rand-dollar exchange rate, the gold price in dollars and orthogonalised returns on the JSE All Share Index that fulfil the role of a catch-all proxy for other influences (see Burmeister \& Wall 1986; Liow 2004). Accordingly, the main aim of this study is to observe whether investment in gold mining stocks (as represented by the Gold Mining Index) can also be considered a safe haven because of an identifiable relationship between movements in the gold price and movements in the value of the index. The period from 2006 to 2013 is investigated, separated into three economic cycles, namely the metals 
boom (January 2006 to November 2007), the global financial crisis (December 2007 to June 2010) and post the global financial crisis (July 2010 to December 2013), as identified and recognised by Baur and Lucey (2010), Baur and McDermott (2010), Humphreys (2010), Jones (2009) and Shafiee and Topal (2010). To do so, the multifactor specification referred to above is re-estimated for each period to isolate the periodic changes in the sensitivity of returns to the gold price. Subsequently, Chow's break point test is applied to confirm or disprove the presence of distinct structural break points, as suggested by the literature, across the three economic cycles outlined above.

This study contributes to the current body of knowledge by firstly extending the research into the relationship between the gold price and gold mining stock prices, as measured and quantified by the gold beta in regression analysis, initiated by McDonald and Solnick (1977) and Tufano (1998) to the analysis of this relationship in the fertile research ground provided by the global financial crisis. Secondly, this study investigates the relationship in a South African context, which previous research has found to differ from the context of developed countries (Faff \& Hillier 2004). Thirdly, this study applies the approach of Fang et al. (2007) to divide the period of investigation into three sub-periods to investigate the possible change in the relationship between the gold price and gold mining stocks, thereby extending the current literature on the relationship between these variables during times of change.

The results of the study are of interest to researchers, investors, market analysts and the management of gold mining companies as they provide insight into the movement of gold mining stock prices in response to movements in the gold price and the exchange rate. The next section is a discussion of the literature from previous studies on this topic, followed by the methodology employed in the study and the results including the discussion and implications thereof, after which the final section concludes.

\section{Literature review}

\section{Gold as an investment}

Gold is both a commodity and a financial asset; it has the same characteristics as money, namely that of a store of wealth, a medium of exchange and a unit of value (Solt \& Swanson 1981). Fei and Adibe (2010) state that gold has characteristics that are distinct and unique from other commodities and that, throughout history, gold has also been used as a means of exchange. Gold not only reflects its own value but also reflects the value of the currency in which it is quoted; a unique characteristic no other commodity holds (Arayssi 2013). This makes gold a currency in its own right. Gold also has several industrial uses alongside its traditional use as a base metal for jewellery. Notably, the value of gold is not dependant on debt, future cash flows or earnings and is therefore less risky.

The Standard and Poor's Goldman Sachs Commodity Index indicates that, over a 30-year period from 1979 to 2009, the gold index generally followed the same trend as the commodities index. However, this trend was broken in 2009, during the peak of the global financial crisis, when the gold index moved upwards and in the opposite direction to the commodities index (Baur \& McDermott 2010). The gold price appears to increase in times of uncertainty while other asset prices generally decrease. The reason for increases in the price of gold during times of economic slowdown and economic hardships is attributed to investors switching to the gold market when they begin to lose trust in financial markets (Shafiee \& Topal 2010).

Humphreys (2010) noted a 'metals boom' that existed from the early 2000s to 2008, when metal prices increased rapidly. This was followed by a slowdown from the beginning of 2008 onwards. During the so-called 2008 global financial crisis, several mineral commodities and equities dropped by around $40 \%$, while gold showed an increase of $6 \%$ (Shafiee \& Topal 2010). From December 2008 to June 2009, when the global crisis was at its peak, the gold index showed a definite upward movement, while the commodity index was at its lowest. Taking into account the theoretical elasticity of gold mining stocks, as developed by Blose and Shieh (1995) and again tested by Blose (1996), the return on an investment in gold mining companies should result in a similar return to an investment in gold itself. According to Fei and Adibe (2010), the world saw a substantial increase in the use of gold as a safe investment following the global financial crisis. Gil-Alana et al. (2015) observe the cyclical nature of the gold price and postulate that precious metals give investors valuable diversification opportunities and that gold in particular can act as a hedge against inflation in times of economic hardship. Gold exhibits further evidence of inflation hedging abilities as it is shown not to add any systematic risk to an investor's portfolio (McCown \& Zimmerman 2006). This is in line with risk management theory, stating that hedging increases shareholder wealth (Fang et al. 2007). According to McCown and Zimmerman (2006) the APT indicates that gold bears virtually no market risk, with an estimated beta close to zero, suggesting that it is advisable to include gold in the portfolio of an investor as a diversification and lowrisk asset. Baur and McDermott (2010) demonstrate that gold has been used to hedge against a decrease in the value of the dollar and inflation.

Dempster and Artigas (2009) argue that gold can be both a tactical inflation hedge and a long-term strategic asset. They find that, in times of high inflation, gold is likely to perform just as well as other common inflation hedges and better than most traditional financial assets. Lawrence (2003), using US data, highlights the main difference that distinguishes gold from other assets, namely that gold is not affected by changes in the business cycle. Lawrence (2003) also finds that the rates of return on other commodities, including mineral commodities, are correlated to US macroeconomic factors, whereas the real rate of return on gold is uncorrelated to US macroeconomic factors. However, this contrasts with the findings of Baker and Van-Tassel (1985), Labys, Achouch and 
Terraza (1999) and Tully and Lucey (2007), who find that metal prices in general respond to macroeconomic factors.

Hemavathy and Gurusamy (2014) study the impact of gold prices on the Indian stock market during the global financial crisis and find that investors started to turn to safe haven assets such as gold during this period. As the rupee depreciated, gold prices in India appreciated considerably, which presented gold as an ideal hedge against exchange rate exposure. Bhunia and Mukhuti (2013) find evidence that gold shows strong safe haven qualities and the price of gold tends to increase in situations where the stock market deteriorates or the dollar worsens. The findings of Gil-Alana et al. (2015) confirm the findings by Hemavathy and Gurusamy (2014) - gold can be viewed as a safe haven in times of crisis or adverse economic pressure. These attributes allow gold to be used as a financial hedge against inflation and an addition to an investor's portfolio. Baur and McDermott (2010) and Dempster and Artigas (2009), as well as several others, illustrate how gold has been relied upon globally as both an inflation hedge and a currency hedge. Nattrass (1995) demonstrates this aspect of gold as a hedge against inflation and currency exposure in South Africa. The question that now arises relates to the nature of the relationship between the gold price and returns for the gold mining industry.

\section{The relationship between gold prices and mining company stock prices}

Investment in gold can be achieved through various channels, including investment in bullion itself, investment in gold coins and investment in gold jewellery. However, investing through these channels is generally expensive because of the high transaction costs involved, and some investors may be restricted in their options to invest through these channels (see Blose 1996; Gilmore et al. 2009). To these investors, investment in gold mining company stocks may be an attractive alternative investment channel through which to diversify into gold. McDonald and Solnick (1977) investigate the relationship between the gold price and the value of gold mining company stocks and identify a statistically significant positive correlation between the two variables. However, Khoury (1984) and Rock (1988) argue that investment in gold mining company stocks is an inadequate alternative for investment in gold. The debate on the extent and pervasiveness of this relationship has continued into the 21st century (Arayssi 2013; Fang et al. 2007; Twite 2002).

The main critique by Khoury (1984) and Rock (1988) with reference to substituting investment in gold bullion with investment in gold mining company stocks revolves around the argument that various other factors influence the movement in gold mining company stock prices, besides the movement in the price of gold itself. Both Khoury (1984) and Rock (1988) argue that an investment in gold mining company stocks is subject to non-gold-related risk factors to such an extent as to render it unviable as an alternative diversification tool for an investment in gold itself.
The value of gold mining company stocks in an investment portfolio was investigated by Jaffe (1989), who finds that including gold mining company stocks in a portfolio (as opposed to gold bullion) increases returns at the expense of an increase in risk. However, the increase in return was found to outweigh the increase in risk. Notably, Jaffe (1989) comments on the relationship between the gold price and gold mining company stock price movements and finds that a $1 \%$ increase in the gold price should lead to a $1 \%$ increase in the value of gold mining company stocks. However, the adjusted coefficient of determination, $\bar{R}^{2}$, was just above 0.4 , indicating that there are other factors that also extensively impact gold mining company stocks.

Blose and Shieh (1995) suggest that the value of gold mining company stocks is determined by the movements in the gold price, the production costs of mining gold, the level of gold reserves in the company's gold mines, and importantly, the level to which the company is diversified into assets and businesses not related to gold mining. Blose and Shieh (1995) find that, for mining companies primarily invested in gold mining, the price elasticity of the companies' stock values is greater than one relative to the gold price. This finding by Blose and Shieh (1995) suggests that gold mining companies may actually be leveraged investments in gold. Therefore, if the gold price moves in an upward direction, the company stock prices should also increase in value but to a greater extent than the gold price. Evidently the inverse is also true; if the gold price decreases, the value of gold mining companies should decrease to a greater extent. ${ }^{1}$

Blose (1996) investigates the relationship between the movement in the gold price and the returns on gold mutual funds and also finds evidence of a leveraged relationship between the two variables, with gold mutual funds being more volatile compared to the gold price. ${ }^{2}$ However, the studies of Blose (1996) and Blose and Shieh (1995) finds the $\bar{R}^{2}$ to be around and below 0.5 , indicating that a substantial extent of variation in gold mining company stock values is not directly related to the gold price. The relatively low $\bar{R}^{2}$ supports arguments by Khoury (1984) and Rock (1988) relating to the influence of non-goldrelated risk factors.

Tufano (1998) undertakes a study of gold mining companies in the USA and Canada and finds further evidence that investment in gold mining company stocks represents a leveraged investment in gold but again that other factors significantly influence gold mining company stock prices. However, Tufano (1998) finds that the gold beta for mining companies differs between different time periods. The study also suggests that mining company stocks are less responsive

1.Various studies corroborate this suggestion. The magnitude of the response of gold mining companies to changes in the gold price will henceforth be referred to as the 'gold beta'. If the value of stocks of gold mining companies increases (decreases) by $1 \%$ for an increase (decrease) of $1 \%$ in the gold price, the beta is one. If the value of the percentage change in the gold price, the beta is higher (lower) than one.

2.Therefore, if the gold price increases by $1 \%$, the value of gold mining stocks would increase by a larger percentage. Consequently, the beta would be higher than 1. 
if the gold price exceeds certain levels. A possible explanation presented by Tufano (1998) is that the relative difference between the gold price and production cost affects the elasticity of the gold price and company stock price relationship. Another important finding is that the level of gold reserves hedged, for example by selling production forward in order to fix the sales price of gold, impacts the relationship between gold price movements and the movements in gold mining stock. Blose and Shieh (1995), Nangolo and Musingwini (2011) and Tufano (1998) suggest that the relationship between gold prices and gold mining company stocks is the result of the gold price being a key input in the future cash-flow generation forecasts for gold mining companies. This entails that, when the company is valued according to expected cash flows, changes in the gold price will affect the stock price (Nangolo \& Musingwini 2011). In South Africa, the Gold Mining Index does not differentiate between mining companies based on their hedging practices, and frequent information on company hedging practices is limited.

Faff and Hillier (2004) find that the magnitude of the relationship between the gold price and the gold mining company stock prices in Australia and South Africa differs from North American countries. For example, Twite (2002) find that Australian gold mining companies have a gold beta of less than one (0.76). With reference to South African gold mining companies, Faff and Hillier (2004) find that the company stock prices do not respond as directly to changes in the gold price as do stock prices in other countries (North American countries and Australia). Faff and Hillier (2004) argue that the findings for South Africa were influenced by the very illiquid nature of South African gold mining company stocks on the JSE. However, this study covers the period between 1993 and 1999. During this time, South Africa was in a reintegration phase with international markets and the JSE was becoming more accessible to international investors. Liquidity on the JSE has subsequently increased significantly, warranting a new investigation into the gold price and gold mining company stock value relationship in South Africa.

In an indication of how the gold beta may change over time, Fang et al. (2007) find a gold beta larger than one for Australian gold mining companies for the period between 1995 and 2000. This differs significantly from the 0.76 beta reported by Twite (2002) for the period between 1985 and 1998. Similarly to the current study, Fang et al. (2007) divide their investigation into sub-periods to investigate the changes in the relationship during different periods within their sample period. Their study investigated the different periods surrounding the so-called collapse of the gold price during the latter part of the 1990s. Fang et al. (2007) report that betas range between 1.02 and 1.85 for their various sub-periods. The lowest beta was recorded for the period when the gold price had resurged after its collapse. This finding corresponds with that of Fang et al. (2007) and Tufano (1998). Gilmore et al. (2009) present an alternative view by showing that gold mining indices from various countries impact the gold price but no evidence that the gold price impacts the gold mining indices. Gilmore et al.'s findings indicate that investors move to gold mining stocks, and not to investments in gold directly, during periods of adverse general stock market movements. The authors cite difficulties investors experience in attempts to invest in gold directly as a possible reason for the preference for gold mining company stocks. According to Gilmore et al., an increase in the price of gold mining company stocks may signal to investors to consider investing in gold itself. This view is contrary to the bulk of literature available on the relationship between gold prices and gold mining company stock prices.

The relationship between gold prices and gold mining company stocks identified in developed countries needs to be investigated within the context of a developing country. The next section details the research methodology that is followed to investigate this relationship within the South African context.

\section{Methodology}

From the literature it is clear that previous researchers found a definitive relationship between the gold price and the stocks of gold mining companies. However, this relationship has not been tested extensively in South Africa, nor did previous studies include the relationship separately for the metals boom, the global financial crisis or the period following the global financial crisis. The relationships during these distinct periods are important as they highlight the possible effect that a significant economic shock, such as the credit crunch, may have on the gold price and company stock price relationship. Findings by Fang et al. (2007) indicate the fact that this relationship cannot be expected to remain constant during different economic cycles - an aspect that is considered by the present study.

This study makes use of a multifactor model implied by the $\mathrm{APT}$, to investigate the extent to which the stock prices of gold mining companies listed on the South African JSE are affected by changes in the gold price (stated in US dollars) and other factors that are not explicitly reflected in the multifactor model but are controlled for by the orthogonalised returns on the JSE All Share Index (see Czaja, Scholz \& Wilkens 2010; Liow 2004). This is supplemented with an investigation into the impact of changes in the rand-dollar exchange rate on gold company stock prices, seeing that the global gold price is quoted in US dollars. We also recognise that other general economic factors and the general economic state can also affect the stock price of gold mining companies (see Khoury 1984; Rock 1988). Following APT tradition, these non-gold-related and general factors are proxied for by using residualised (orthogonalised) returns on the JSE All Share Index (see Burmeister and Wall 1986; Czaja et al. 2010). ${ }^{3}$ The study is further divided into three distinct periods, to

3.The market index is assumed to fulfil the role of a catch-all proxy for omitted variables and therefore should mitigate under specification that may arise as a variables and therefore should mitigate under specification that may arise as a
result of the parsimonious nature of the model (Berry, Burmeister \& McElroy 1988; Van Rensburg 1996). 


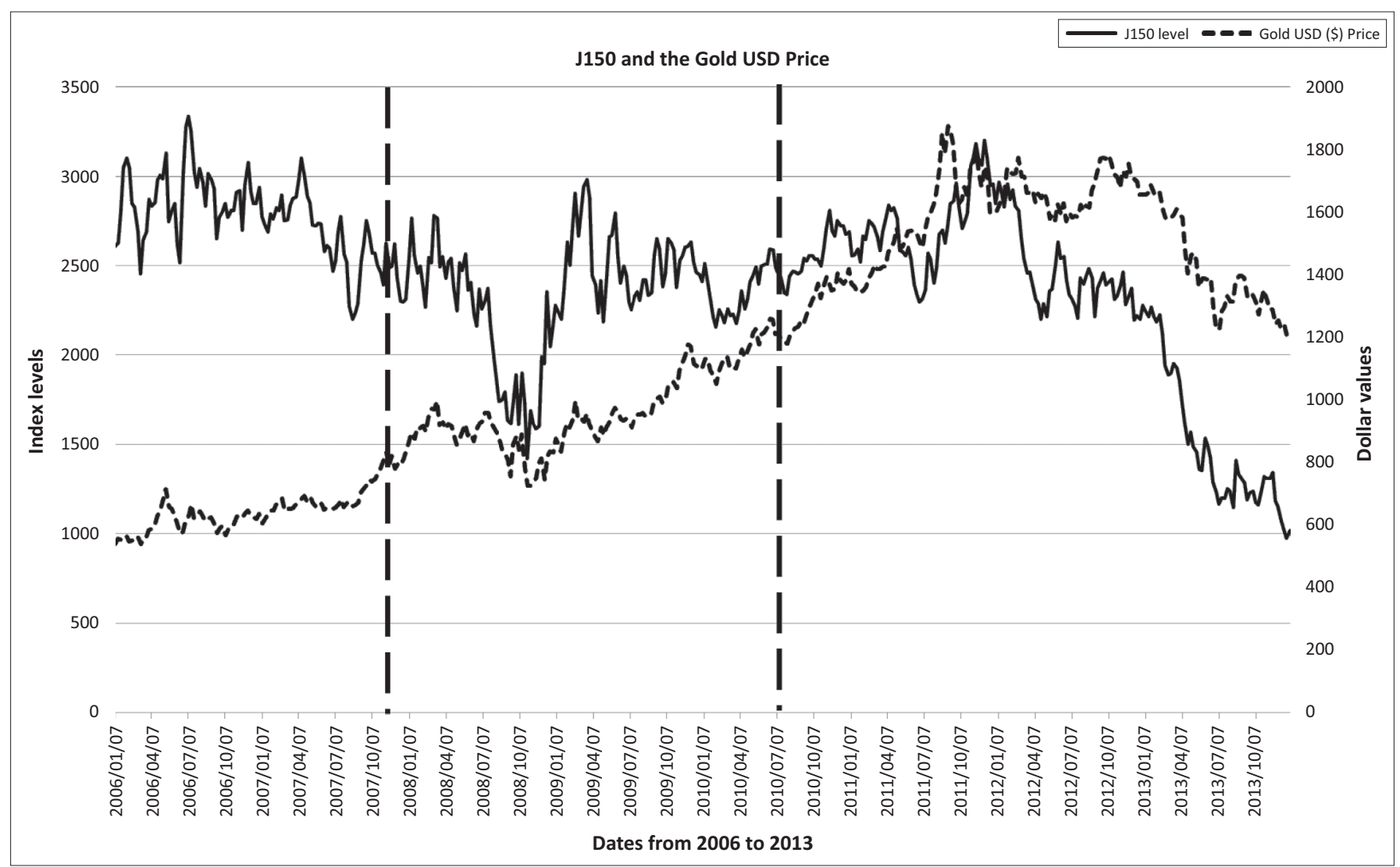

FIGURE 1: Movement in the JSE Gold Mining Index (J150) and the gold price in dollars (January 2006 to December 2013). J150, Johannesburg Stock Exchange Gold Mining Index.

find evidence of the extent to which specific global economic occurrences impact the relationships between the stock prices of gold mining companies, the gold price quoted in dollars and the rand-dollar exchange rate.

\section{Data}

The data used in this study were obtained from the INET BFA database and were of a weekly frequency for January 2006 to December 2013. ${ }^{4}$ In accordance with Fang et al. (2007), this period is divided into three sub-periods. The sub-periods for this study are as follows:

- January 2006 to November 2007 - the metals boom (Humphreys 2010)

- December 2007 to June 2010 - the global financial crisis, a period of significant interest in terms of the behaviour of gold prices (Baur \& McDermott 2010; Shafiee \& Topal 2010) and share market indices (Baur \& Lucey 2010)

- July 2010 to December 2013 - after the global financial crisis, a period after an economic shock, being of interest according to Fei and Adibe (2010).

The primary variables of interest, namely the JSE Gold Mining Index (J150) and the gold price in dollars, are set out in Figure 1, with the respective sub-periods denoted by the dashed vertical lines.

4.In preliminary analysis, both daily data and weekly data were obtained from the INET BFA database. An analysis of the daily data showed a high number of missing observations. To avoid extensive interpolation and the associated potential biases observations. To avoid extensive interpolation and the associated
associated with using interpolated data, weekly data was used.
Formally, returns are defined as the natural logarithm of weekly returns see Equation 1:

$R_{G M t}=\ln S_{G M t}-\ln S_{G M t-1}$

[Eqn 1]

where $R_{G M t}$ is the return on the gold mining industry at time $t$ and $S_{G M t}$ is the level of the JSE Gold Mining Index at time $t$. There are currently ten gold mining companies listed on the JSE with complete information available on the INET BFA database. By selecting the JSE Gold Mining Index, the entire gold mining industry is represented in the study. The total population of South African mining companies is relatively small, which makes it impossible to employ proper random sampling (see Vize et al. 2009). Other returns or changes in the variable series used in the analysis, namely the gold price in dollars $\left(R_{G U t}\right)$, the rand-dollar exchange rate $\left(R_{Z U t}\right)$ and the JSE All Share Index (J203) $\left(R_{M t}\right)$, are calculated in the same manner (Eqn 1). Descriptive statistics for these variables are presented in Table 1.

Table 1 indicates widespread departures from normality in the form of skewness and excess kurtosis, confirmed by significant Jarque-Bera test statistics for all series. Departures from normality in financial time series are widely recognised in the literature, and the results presented here attest to this (see Xiao \& Aydemir 2007). Furthermore, all series are positively skewed, with the exception of the series of changes in the gold price, which is negatively skewed. Table 2 reports on the serial correlation structure and the stationarity of the variable series. 
TABLE 1: Descriptive statistics for the data set (January 2006 to December 2013).

\begin{tabular}{lccccccc}
\hline Variable & Mean & SD & Skewness & Kurtosis & JB stat & Max & Min \\
\hline$R_{G M t}$ & -0.002 & 0.053 & 0.390 & 4.987 & $79.006^{*}$ & 0.216 & -0.202 \\
$R_{G U t}$ & 0.002 & 0.029 & -0.417 & 4.955 & $78.433^{*}$ & 0.128 & -0.133 \\
$R_{Z U t}$ & 0.001 & 0.025 & 0.178 & 5.992 & $157.380^{*}$ & 0.104 & -0.134 \\
$R_{M t}$ & 0.002 & 0.028 & 0.035 & 7.161 & $300.196 *$ & 0.160 & -0.096 \\
\hline
\end{tabular}

JB stat, Jarque-Bera test statistic. The JB test is used as a test of normality (Jarque \& Bera 1987). The total number of observations for the full sample period is 416 .

SD, Stander deviation; Max, Maximum; Min, Minimum; *, Statistical significance at the $10 \%$ level.

TABLE 2: Serial correlation structure and the stationarity of the variable series, full period (January 2006 to December 2013).

\begin{tabular}{llclcc}
\hline Variable & $\rho_{1}$ & $\boldsymbol{Q}(5)$ & $\boldsymbol{Q}(\mathbf{1 0})$ & $\mathrm{ADF}$ & $\mathrm{PP}$ \\
\hline$R_{G M t}$ & $-0.106 * *$ & $11.921 *$ & $24.483 * * *$ & $-22.596 * * *$ & $-23.238 * * *$ \\
$R_{G U t}$ & -0.037 & 5.041 & 9.079 & $-21.113 * * *$ & $-21.358 * * *$ \\
$R_{Z U t}$ & $-0.117 *$ & $17.049 * * *$ & $21.242 * *$ & $-22.856 * * *$ & $-22.801 * * *$ \\
$R_{M t}$ & $-0.114 *$ & $9.357 *$ & $16.402 *$ & $-22.769 * * *$ & $-22.836 * * *$ \\
\hline
\end{tabular}

$R_{M t}$ the first order serial correlation coefficient: Q-statistics, Ljung-Box test statistics that test whether serial correlation coefficients are jointly equal to zero at the 5th and 10th orders (Ljung \& Box 1978); ADF, augmented Dickey-Fuller; PP, Phillips-Peron (PP) unit root test (Dickey \& Fuller 1979; Phillips \& Perron 1988); Lag selection, is based upon the Schwarz's information criterion where applicable; * Statistical significance at the $10 \%$ level; **, statistical significance at the $5 \%$ level; $* * *$, statistical significance at the $1 \%$ level.

The results in Table 2 suggest that the assumption of independence is violated for returns on the gold mining INDEX, fluctuations in the exchange rate and returns on the JSE All Share Index. This is somewhat unexpected; financial data is widely assumed to be serially uncorrelated (see Cont 2001)..$^{5}$ This violation can be attributed to the presence of outliers, which Brooks (2008) argues may be responsible for serial correlation, especially if these outliers are close together. It is perhaps telling that three of the four variables, namely returns on the gold mining industry, the JSE All Share Index and fluctuations in the exchange rate, are highly sensitive to financial crises, which can potentially result in significant outliers. Box plots that identify both near and far (extreme) outliers indicate that a number of observations that can be classified as outliers are clustered around the later 2008 period that coincides with the hight of the global financial crisis. This suggests that outliers are indeed a possible explanation for the lack of statistical independence. Following preliminary analysis, each of the three series was pre-whitened, by using an autoregressive time series methodology, so as to ensure that any established relationships were not spurious in nature (see Poon \& Taylor 1991; Priestley 1996). To confirm that the pre-whitening process did not remove important information, correlations between the original and prewhitened variables were examined. All correlation coefficients were found to be above 0.98 , suggesting that the pre-whitened variable series approximated the original series closely. The final tests reported upon, the augmented Dickey-Fuller and the Phillips-Peron tests, indicate that all the series are stationary - an expected outcome for differenced data.

Panel A of the correlation matrix in Table 3 provides preliminary insight into the relationships between the

5.Cont (2001: 224,229$)$ argues that autocorrelation in returns is often insignificant
and that it is well known that markets do not exhibit significant autocorrelation (also and that it is well
see Fama 1965).
TABLE 3: Correlation matrix for the full period (February 2006 to December 2013).

Panel A: Full period

\begin{tabular}{lcccc}
\hline Variable & $\boldsymbol{R}_{G M t}$ & $\boldsymbol{R}_{G U t}$ & $\boldsymbol{R}_{Z M t}$ & $\boldsymbol{R}_{M t}$ \\
\hline$R_{G M t}$ & 1 & - & - & - \\
$R_{G U t}$ & $0.602 * * *$ & 1 & - & - \\
$R_{Z U t}$ & $-0.103 * *$ & $-0.301 * * *$ & 1 & - \\
$R_{M t}$ & $0.420 * * *$ & $0.285^{* * *}$ & $-0.450 * * *$ & 1 \\
\hline
\end{tabular}

Panel B: Sub-periods

\begin{tabular}{lccc}
\hline & MB & GFC & AGFC \\
\hline$R_{G U t}$ & $0.640 * * *$ & $0.631 * * *$ & $0.530 * * *$ \\
$R_{Z U t}$ & -0.051 & $-0.201 * *$ & 0.048 \\
$R_{M t}$ & $0.640 * * *$ & $0.391 * * *$ & $0.353 * * *$ \\
\hline
\end{tabular}

$\mathrm{MB}$, metals boom; GFC, global financial crisis; AGFC, after global financial crisis. *, Statistical significance at the $10 \%$ level; **, statistical significance at the $5 \%$ level; ***, statistical significance at the $1 \%$ level.

(pre-whitened) variables over the full period. Notably, all factors are significantly correlated with returns on the gold mining industry, which provides preliminary evidence of a relationship between gold mining industry returns and the gold price, the exchange rate and returns on the JSE All Share Index. Although the gold price, the exchange rate and returns on the JSE All Share Index are significantly correlated, correlations are below 0.5 and therefore unlikely to result in a multicollinearity problem, although this cannot be excluded without first undertaking a preliminary analysis (see Poon \& Taylor 1991).

Panel B of Table 3 reports the correlation between returns on the gold mining industry and each of the variables over the three sub-periods. Significant correlation coefficients suggest that the relationship between the returns on the gold mining industry, the gold price and returns on the JSE All Share Index persists over the sub-periods. However, the correlation between the exchange rates is significant only for the period of the global financial crisis, which suggests that this relationship is not stable or persistent. It is at this stage that returns on the JSE All Share Index are residualised so as to account for factors beyond the factors included in the model (see Wurm \& Fisicaro 2014). ${ }^{6}$

\section{Analysis}

Regression analysis is used to test and study the relationships between returns on the gold mining industry, the gold price and the exchange rate. McDonald (2014) states that linear regression is the most suitable statistical method for a variety of applications, as it determines if one variable is associated with another variable and measures the strength of such a relationship. To estimate and quantify the relationships, a similar approach to that of Twite (2002) is taken whereby a set of univariate and multifactor models is estimated, the latter representing a specification

6.The OLS methodology was used in residualisation. To establish whether the residualised variables retain the properties of the original variables (prior to prewhitening and residualisation), correlations and plots were compared. The correlation coefficient for the residualised JSE All-Share Index return series is 0.89 and 0.95 for the gold price. The correlations between these two variables and returns on the gold mining industry, relative to those reported in Table 2, remain virtually the same. Univariate regressions of the original variables onto the residualised variables produce $\beta$ s of 1 . This suggests that the residualised variables closely resemble the original variables. 
motivated by the MULTIFACTOR APT. These models are set out below:

$R_{G M t}=\beta_{G U} R_{G U t}+\varepsilon_{i t}$

$R_{G M t}=\beta_{Z U t} R_{Z U t}+\varepsilon_{i t}$

$R_{G M t}=\beta_{M t} R_{M t}+\varepsilon_{i t}$

$R_{G M t}=\beta_{G U} R_{G U t}+\beta_{Z U t} R_{Z U t}+\beta_{M t} R_{M t}+\varepsilon_{i t}$

where $R_{G M t}$ represents the returns for the gold mining industry in Equations $2-5, R_{G U t}$ is the change in the dollar denominated gold price (as before) ${ }^{7}$ and $R_{Z U t}$ is the change in the rand-dollar exchange rate. The returns on the JSE All Share Index are denoted by $R_{M t}$ in Equations 4 and 5 . Sensitivities to these variables are represented by the respective betas $(\beta \mathrm{s})$. Equations $2-4$ are univariate regressions used to gain preliminary insight into the explanatory power of each of the variables, and Equation 5 is the unrestricted model, the multifactor specification that is the focus of the analysis.

As the full sample period of January 2006 to December 2013 is turbulent and spans three hypothetically distinct periods, the structural stability of Equation 5 was tested using the CUSUM test. The Chow break point test ${ }^{8}$ was then applied to test whether there are indeed three distinct sub-periods as suggested by Baur and McDermott (2010), Fei and Adibe (2010), Humphreys (2010) and Shafiee and Topal (2010). Analysis was also conducted on each sub-period by estimating Equation 5 (for each sub-period). This permitted an analysis of the (potentially changing) relationship between returns on the gold mining industry, the gold price and the exchange rate across sub-periods by comparison of the exposure profile across the three sub-periods and the full period.

\section{Results}

Table 4 reports the results of least squares regressions for Equations 2-5 over the full period. Standard errors were estimated using a Newey and West (1987) heteroscedasticity and autocorrelation coefficient consistent covariance matrix.

The results in Table 4 in Panel A indicate that, as expected, the relationship between returns for the gold mining industry and the gold price is positive and statistically significant, which is in line with the findings of Blose and Shieh (1995), Fang et al. (2007), McDonald and Solnick (1977), Nangolo and Musingwini (2011), Tufano (1998) and Twite (2002). In line with a priori expectations, the gold price beta, $\beta_{G U t^{\prime}}$ is positive. Wald's test of linear restrictions constrains the $\beta_{G U t}$ to one, and the null hypothesis is rejected at the $10 \%$ level of

7.The US dollar denominated gold price is used to avoid confounding the impact of the exchange rate and the gold price on gold mining returns. If the gold price was denominated in rands, then any changes in the rand denominated gold price could value of gold. Therefore, $R_{z}$ fulfils the role of a theoretically justifiable control value of gold. Therefore, $R_{Z U_{t}}$ fulfils the role of a theor
variable and measures the impact of the exchange rate.

8.See Brooks (2008) for a discussion of these tests.
TABLE 4: Least squares model results.

\begin{tabular}{lcccc}
\hline Variables & Panel A & Panel B & Panel C & Panel D \\
\hline Intercept & $-7.05 \mathrm{E}-05$ & $4.60 \mathrm{E}-06$ & $-4.65 \mathrm{E}-05$ & $-9.51 \mathrm{E}-05$ \\
$\beta_{G U t}$ & $1.130 * * *$ & - & - & $1.023 * * *$ \\
$\beta_{Z U t}$ & - & -0.217 & - & -0.218 \\
$\beta_{M t}$ & - & - & $0.877 * * *$ & $0.678 * * *$ \\
$\bar{R}^{2}$ & 0.358 & 0.011 & 0.175 & 0.470 \\
AIC & -3.480 & -3.047 & -3.229 & -3.663 \\
$F$-statistic & $228.610 * * *$ & $4.389 * *$ & $86.920 * * *$ & $120.684 * *$ \\
AR(1) & $2.949 *$ & 0.029 & 0.905 & 0.504 \\
AR(5) & $2.015 *$ & 0.893 & 0.732 & 0.862 \\
ARCH(1) & $44.094 * * *$ & $7.502 * * *$ & $21.410 * * *$ & $26.300 * * *$ \\
ARCH(5) & $84.128 * * *$ & $28.164 * * *$ & $7.920 * * *$ & $10.445 * * *$ \\
\hline AIC, $A$ A & & & &
\end{tabular}

AIC, Akaike information criterion; *, Statistical significance at the $10 \%$ level; **, statistical significance at the $5 \%$ level; ***, statistical significance at the $1 \%$ level.

significance, suggesting that $\beta_{G U t}$ is not equal to one (see McMillan \& Ruiz 2009). This result should, however, be approached with caution because it is possible (if not likely) that the restricted model is underspecified and this results in an upward bias of the $\beta_{G U t}$ (see Gujarati \& Porter 2009). Moreover, Blose (1996), Khoury (1984) and Rock (1988) allude to the fact that a positive relationship between the gold price and the stocks in gold mining companies can be attributed to other factors. The adjusted coefficient of determination, $\bar{R}^{2}$, of this restricted model is 0.358 , suggesting that, as expected, the gold price explains a substantial amount of variation in the returns for the gold mining industry. The results in Panel $\mathrm{B}$ indicate that returns for the gold mining industry are negatively related to fluctuations in the exchange rate. However, the relationship is not statistically significant. As suggested in Panel B of Table 3, a significant relationship most likely arose during the global financial crises as the correlation coefficient between returns for the gold mining industry and the exchange rate is Please replace this with a -0.201 for this sub-period but insignificant for the other subperiods. The results in Panel C of Table 4 indicate that gold mining industry returns are positively related to the (residualised) market index. The market beta, $\beta_{M t^{\prime}}$ is 0.877 , which suggests that the gold mining industry is less sensitive to market movements and other factors relative to fluctuations in the gold price. This is supported by the lower $\bar{R}^{2}$ of 0.175 . As with the univariate regressions in Panel A, it is likely that $\beta_{M t}$ exhibits upward bias. The results of the unrestricted version of the model are reported in Panel D. While both $\beta_{G U t}$ and $\beta_{M t}$ are significant, $\beta_{Z U t}$ remains insignificant and almost unchanged. $\beta_{G U}$ and $\beta_{M t}$ decrease in size, which suggests that a combination of all three factors decreases or eliminates bias that is attributable to omitted variables. ${ }^{9}$ Wald's test of coefficient restrictions is applied with all coefficients constrained to zero and based upon the resultant $F$-statistic; the null hypothesis is rejected. This confirms the joint significance of all variables in the specification and therefore the appropriateness of this multifactor specification (Brooks 2008; Sadorsky \& Henriques 2001). To test parameter stability, the CUSUM test was applied.

9.See Berry et al. (1988: 31) and Burmeister and Wall (1986: 10) for a discussion of the role of a residual market factor and by implication, the market index from which a residual market factor is derived. 


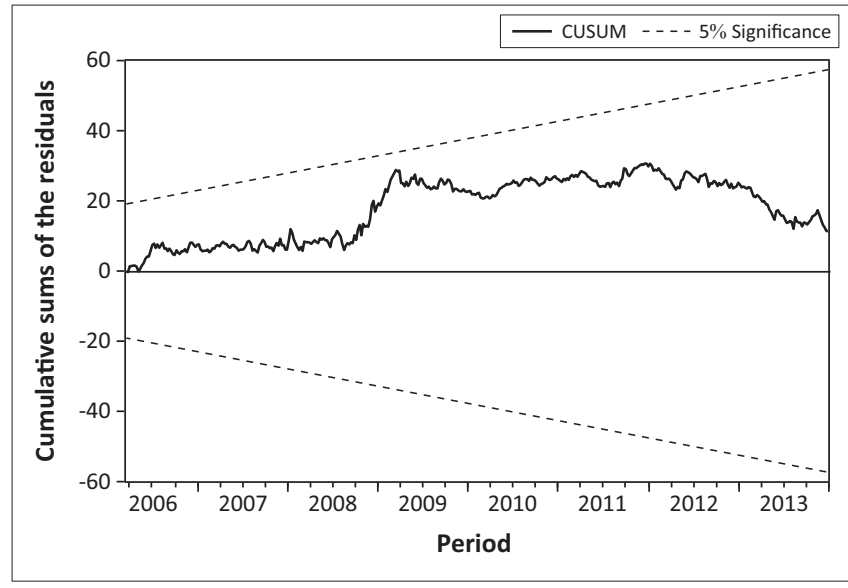

FIGURE 2: Cumulative sum control chart.

The graph in Figure 2 indicates that the CUSUM test statistic does not move beyond the $95 \%$ confidence interval, suggesting that the null hypothesis of stability is not rejected (see Brooks 2008; Ploberger \& Krämer 1992). To further investigate stability and confirm the existence of break points identified in the literature, the Chow break point test was applied with December 2007 and July 2010 as multiple designated break points. The results are ambiguous; out of two reported test statistics, the log likelihood ratio test statistic is marginally significant at the $10 \%$ significance level whereas the F-statistic is marginally insignificant, implying that there is a potential structure break over the entire period. To investigate this further and to isolate this potential break point, the model is re-estimated for consecutive two subperiods at a time with the global financial crisis common to both sub-periods. The results of Chow's break point test are reported in Table 5.

The results indicate that, while there was no structural break between the metals boom and the global financial crisis, a structural break exists between the global financial crises and the period after the global financial crisis (December 2010). The F-statistic and log likelihood ratio are statistically significant at the $10 \%$ level of significance. These findings suggest that the ambiguous results for the full period in Table 5 are driven by a structural break that exists between the global financial crisis and the period after the global financial crisis. To eliminate the possibility that structural breaks exist during the metals boom and global financial periods but do not coincide with the dates suggested by Humphreys (2010) and Jones (2009), the Quandt-Andrews break point test for one or more unknown structural break points is applied. The Quandt-Andrews test differs from Chow's break point test in that no predetermined break points need to be defined and is therefore useful in confirming that there are no other likely unknown break points (see Narayan \& Narayan 2010). Results indicate that the null hypothesis of no break points over this period cannot conclusively be rejected, which suggests that the South African gold mining industry did not experience a significant structural shift on account of the global financial crisis. This cannot, however, be said about the global financial crisis and
TABLE 5: Break point test results.

\begin{tabular}{lccc}
\hline Period & Full & MB/GFC & GFC/AGFC \\
\hline Break point & Dec 2007 and July 2010 & Dec 2007 & July 2010 \\
$F$-statistic & 1.657 & 16.523 & $2.045^{*}$ \\
Log likelihood ratio & $13.432 *$ & 6.749 & $8.283^{*}$ \\
\hline
\end{tabular}

Full, refers to estimation over the full period, January 2006 to December 2013; MB/GFC, metals boom and global financial crisis (between January 2006 and June 2010); GFC/AGFC, global financial crisis and after global financial crisis (between December 2007 and December 2013); *, Statistical significance at the $10 \%$ level.

Note: Full Column (Chow's Breakpoint test used). The two remaining columns - Quandt Andrews test used.

TABLE 6: GARCH(1,1) model results.

\begin{tabular}{lcccc}
\hline Model & Full & MB & GFC & AGFC \\
\hline Intercept & $-4.41 \mathrm{E}-05$ & -0.003 & $0.004 *$ & -0.001 \\
$\beta_{G U t}$ & $1.027 * * *$ & $0.786 * *$ & $1.220^{* * *}$ & $1.002 * * *$ \\
$\beta_{\text {ZUt }}$ & $-0.114 * *$ & -0.137 & $-0.391^{* * *}$ & 0.010 \\
$\beta_{M t}$ & $0.627 * * *$ & $0.902 * * *$ & $0.302 * * *$ & $0.674 * *$ \\
$\omega$ & $6.07 \mathrm{E}-05^{*}$ & 0.000 & $-2.06 \mathrm{E}-05$ & $0.001^{*}$ \\
$\alpha_{1}$ & $0.114 * * *$ & -0.043 & $0.105^{* *}$ & $0.207^{*}$ \\
$\beta_{1}$ & $0.845^{*} * *$ & 0.538 & $0.894 * * *$ & 0.164 \\
$\bar{R}^{2}$ & 0.468 & 0.572 & 0.447 & 0.421 \\
AIC & -3.784 & -3.961 & -3.464 & -3.978 \\
$F$-statistic & $144.692 * * *$ & $39.416 * * *$ & $73.427 * * *$ & $44.224 * * *$ \\
$Q(1)$ & 0.1064 & 0.174 & 1.091 & 0.110 \\
$Q(5)$ & 4.363 & 1.954 & 7.849 & 1.528 \\
$Q^{2}(1)$ & 1.519 & 0.010 & 0.248 & 0.166 \\
$Q^{2}(5)$ & 3.414 & 4.149 & 7.791 & 8.662 \\
ARCH(1) & 1.506 & 0.010 & 0.238 & 0.161 \\
ARCH(5) & 0.654 & 0.796 & 1.493 & $1.883 *$ \\
\hline
\end{tabular}

$F$-statistics are reported for Wald's test of linear restrictions testing the null hypothesis of coefficients jointly equalling zero (McMillan \& Ruiz 2009; Nelson 1991); Q(1) and Q(5), are Ljung-Box test statistics for residual serial correlation at the 1 st and 5th orders; Autoregressive conditional heteroscedasticity models $A R C H(1)$ and $A R C H(5)$, are Lagrange multiplier test statistics for residual ARCH effects at the 1st and 5th orders; *, Statistical significance at the $10 \%$ level; $* *$, statistical significance at the $5 \%$ level; ***, statistical significance at the $1 \%$ level.

the period after the global financial crisis, which suggests that the global financial crisis had a delayed structural impact.

As the residuals of the results of Equation 5 in Table 4 exhibit $\mathrm{ARCH}$ effects, further analysis for both the sub-periods and the full period was undertaken with the volatility dynamics modelled as a function of past shocks and conditional variance (see Bollerslev 1986; Engle 2001). The GARCH(1,1) specification employed was as follows: ${ }^{10}$

$h_{t}=\omega+\alpha_{1} \varepsilon_{t-1}^{2}+\beta_{1} h_{t-1}$

[Eqn 6]

where $h_{t}$ is the conditional variance, $\alpha_{1}$ and $\beta_{1}$ are the weights on the squared residual error terms and past values of variance, represented by $\varepsilon_{t-1}^{2}$ and $h_{t-1}$, respectively. The results of the GARCH $(1,1)$ regression are reported in Table $6 .{ }^{11}$ An alternative to estimating a $\operatorname{GARCH}(1,1)$ model to address $\mathrm{ARCH}$ effects in the residuals of Equation 5 is to use Newey and West (1987) heteroscedasticity and serial correlation consistent standard errors as was done for Equations 2-5.

10.Bollerslev, Chou and Kroner (1992: 10) state that in almost all applications, ARCH and GARCH orders of 1 are sufficient. Residual error terms are assumed to follow the normal distribution, thereby allowing estimators to retain the best, linear unbiased estimator properties under maximum likelihood estimation (Smith \& Hall 1972).

11.While one could proceed to rely on the OLS methodology using heteroscedasticity and serial-correlation consistent standard errors, the GARCH methodology is more attractive for a number of reasons. Refer to Andersen et al. (2003:48) for a attractive for a number of reasons. Refer to Andersen et al. (2003:48) for a
discussion on the advantages of using the GARCH methodology, aside from a model of conditional variance, which is of interest in itself. 
Andersen et al. (2003) argue that estimation within the ARCH/GARCH modelling framework yields more efficient estimates of model coefficients. Additionally, Brzeszczyński, Gajdka and Schabek (2011) and Hamilton (2010) show ARCH-class models produce more accurate (conditional mean) coefficient estimates by utilising information about the volatility dynamics of the residuals. The $\operatorname{GARCH}(1,1)$ model is applied as it is deemed by the literature to be the simplest and most robust volatility model of the ARCH-type models and single $\mathrm{ARCH}$ and $\mathrm{GARCH}$ parameters are deemed to be sufficient for most applications (see Bollerslev, Chou \& Kroner 1992; Engle 2001).

A comparison of results for the full period to those reported in Panel D of Table 4 indicates that, aside from a change in the coefficient on the exchange rate, which is now statistically significant and declines (in absolute terms) from 0.218 to 0.114 , the other estimated coefficients are closely comparable. The gold price beta, $\beta_{G U^{\prime}}$ is now 1.027 in comparison to 1.023 in Table 4 and the market beta, $\beta_{M t^{\prime}}$ is now 0.627 , whereas it was previously 0.678 . With the exception of the exchange rate, $\beta_{Z U t^{\prime}}$ the parameters of the model appear to be stable. In terms of the $\bar{R}^{2}$, the explanatory power of the models is comparable. It is worth noting that for the full period, the $\bar{R}^{2}$ is below 0.5 as in Blose (1996) and Blose and Shieh (1995). The residual diagnostics for the full period do not point towards the presence of the $\mathrm{ARCH}$ effects or serial correlation in the residuals. Results for the sub-periods are also reported in Table 6, and Figure 3 provides a comparison of the exposure profile.

During the metals boom, the gold price played a lesser role in determining returns for the gold mining industry relative to other factors, as measured by the market index. During this period, $\beta_{G U}$ was 0.786 whereas $\beta_{M t}$ was 0.902 . After the metals boom, the $\beta_{G U}$ increased to 1.220 during the global financial crisis and decreased to 1.002 after the global financial crisis. This initial increase in the sensitivity of the gold mining industry to the gold price during the global financial crisis was possibly driven by gold's role as a safe haven during times of crisis. As expected, it appears that the relative importance of the gold price, in determining returns, increased during the global financial crisis and after the crisis, while the

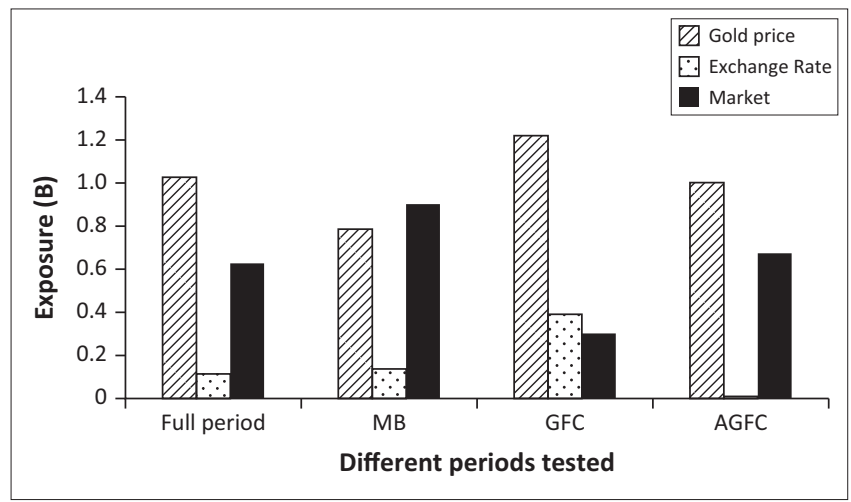

$M B$, metals boom; GFC, global financial crisis; AGFC, after global financial crisis.

FIGURE 3: Exposure of returns (measured by the respective $\beta \mathrm{s}$ ) to the variables in Equation 5 for the full period and sub-periods. impact of other factors, as hypothesised to be captured by the market index, decreased. Similarly to the findings of this study, Tufano (1998) also found that the relationship between the gold price and gold mining company stocks differed for different periods. Although still significant, the $\beta_{M t}$ was 0.302 during the global financial crisis and 0.674 after the global financial crisis, remaining below the 0.902 level measured during the metals boom. While the market index was statistically significant for all sub-periods and during the full period, returns on the gold mining industry seem to be primarily driven by the gold price. The results in Table 6 indicate that the rand-dollar exchange rate was significant during the full period. However, it was only statistically significant during the global financial crisis, which suggests that the statistical significance during the global financial crisis created a bias in favour of significance for the full period. The negative relationship between gold mining industry returns and the exchange rate suggests that a depreciation in the rand-dollar exchange rate resulted in increased returns for the gold mining industry. The significance of the rand-dollar exchange rate during the global financial crisis period can be potentially attributed to this being a time of heightened systematic risk affecting an emerging economy such as South Africa. Kaneko and Lee (1995) see the exchange rate as an internationally orientated variable, which suggests that it captures aspects of international risk. It is noteworthy that the $\beta_{G U}$ was highest during the global financial crisis and also that the $\beta_{z U t}$ was also statistically significant during this period. This was an exceptionally volatile period, with the impact of the gold price likely amplified by increased risk - similar to that of the exchange rate. While the $\beta_{Z U t}$ was -0.391 during the global financial crisis, it was -0.137 during the metals boom, 0.010 after the financial crisis and was of statistical insignificance. This suggests that an overall finding of significance is driven by significance during the global financial crisis and not the other periods.

\section{Conclusions and recommendations}

The concept of investing in gold mining stocks, as an alternative to investing in gold bullion, with the aim of portfolio diversification, especially in times of economic strain, was investigated in this study. A better understanding of this concept is of value to both investors and managers of gold mining companies. This study adds to the current literature by studying the relationship between gold mining industry returns, the gold price and the rand-dollar exchange rate over three distinct periods in the emerging economy of South Africa. These are the metals boom, the global financial crisis and post global financial crisis periods. The main findings can be summarised as follow:

- The returns for the gold mining industry are driven by the gold price, corroborating the current main stream of findings in the relevant research literature. While a relationship between returns and the gold price is observed throughout the entire sample period, an analysis of the sub-periods shows that the importance of the gold price in explaining returns for the gold mining industry 
increases during the global financial crisis and remains more important after the global financial crisis, relative to the period prior to the global financial crisis. This extends the current literature and indicates that the portfolio diversification properties of investment in gold mining stocks are more pronounced during and after periods of financial shocks.

- The rand-dollar exchange rate plays a role in explaining returns during the global financial crisis. The nature of this variable suggests that this is because of the exchange rate accounting for heightened international systematic risk during this period. The effect of heightened international risk is especially relevant to an emerging economy, such as South Africa. While returns for the gold mining industry are significantly related to the exchange rate over the entire sample period, this finding appears to be driven by significance during the global financial crisis period. Therefore, the role the exchange rate plays in explaining gold mining stock returns is ambiguous, and in an emerging economy, appears to be influenced by international systematic risk.

- Findings suggest that there are other factors that are important for gold mining industry returns. While not specified, this is suggested by a finding that the market index, as measured by the residualised JSE All Share Index, is statistically significant throughout the period and the sub-periods. The changing magnitude of the sensitivity of gold mining industry returns to market movements suggests that the importance of these factors changes over time (see Van Rensburg 1996). ${ }^{12}$ This suggests an avenue for further research into the other specific drivers of gold mining industry returns.

We believe that this study extends the understanding of the changing South African gold mining industry in a world that is still recovering from the global financial crisis. The findings of this research are of interest to investors, market analysts and the management of mining companies, as they provide more insight on the expected behaviour of the mining sector in relation to the gold price in different financial circumstances. Specifically, these findings suggest that the price of gold is a relatively more important determinant of returns for gold mining stocks after the global financial crisis than during the metals boom. Furthermore, the rand-dollar exchange rate no longer appears to have a significant impact on returns, whereas the importance of other factors, as summarised by returns on the JSE All Share Index, appears to have also decreased following the global financial crisis. Consequently, this suggests that management should shift their focus in risk management practice and value management and should hedge against fluctuations in gold prices to preserve firm value and to maximise shareholder wealth. Moreover, management should be cognisant that general market conditions will have less of an impact on firm value than before.

Areas for further research that follow from this study are the macroeconomic determinants of gold mining industry

12.Van Rensburg (1996) argues that heightened sensitivity to the residual market factor, and by extension the market index, suggests the omission of factors in a factor, and by extension the market index, suggests the
return generating specification of a given industrial sector. returns in the broader sense and the risk inherent in gold mining stocks and in the gold price from an investor's perspective. The former area is suggested by a finding that the market index, which can be seen as a proxy for factors omitted from the model, explains returns. The latter area may be investigated by studying and comparing the first two moments of the gold mining stock prices and gold. Additionally, there is room for future research into the individual gold betas of the ten mining companies in the population and their importance relative to other companyspecific variables.

\section{Acknowledgements Competing interests}

The authors declare that they have no financial or personal relationships which may have inappropriately influenced them in writing this article.

\section{Authors' contributions}

E.d.T. was the project leader and contributed to the literature review. Z.E. was largely responsible for the literature review. J.J.S. developed the research design and conducted the statistical analyses.

\section{References}

Andersen, T.G., Bollerslev, T., Diebold, F.X. \& Vega, C., 2003, 'Micro effects of macro announcements: Real-time price discover in foreign exchange', The American Economic Review 93(1), 38-62. https://doi.org/10.1257/000282803321455151

Arayssi, M., 2013, 'Price drivers and investment strategies of gold', MPRA Paper $56115,1-8$.

Baker, S.A. \& Van Tassel, R.C., 1985, 'Forecasting the price of gold: A fundamentalist approach', Atlantic Economic Journal 13, 43-52. https://doi.org/10.1007/ BF02304036

Baur, D.G. \& Lucey, B.M., 2010, 'Is gold a hedge or a safe haven? An analysis of stocks, bonds and gold', Financial Review 45(2), 217-229. https://doi.org/10.1111/ j.1540-6288.2010.00244.x

Baur, D.G. \& McDermott, T.K., 2010, 'Is gold a safe haven? International evidence', Journal of Banking \& Finance 34(8), 1886-1898. https://doi.org/10.1016/j. jbankfin.2009.12.008

Berry, M.A., Burmeister, E. \& McElroy, M.B., 1988, 'Sorting out risks using known APT factors', Financial Analysts Journal 44(2), 29-42. https://doi.org/10.2469/faj.v44. $\mathrm{n} 2.29$

Bhunia, A. \& Mukhuti, S., 2013, 'The impact of domestic gold price on stock price indices - an empirical study of Indian stock exchanges', Universal Journal of Marketing and Business Research 2(2), 35-43.

Blose, L.E., 1996, 'Gold price risk and the returns on gold mutual funds', Journa of Economics and Business 48(5), 499-513. https://doi.org/10.1016/S01486195(96)00037-9

Blose, L.E. \& Shieh, J.C.P., 1995, 'The impact of gold price on the value of gold mining stock', Review of Financial Economics 4(2), 125-139. https://doi. org/10.1016/1058-3300(95)90002-0

Bollerslev, T., 1986, 'Generalized autoregressive conditional heteroskedasticity', Journal of Econometrics 31(3), 307-327. https://doi.org/10.1016/03044076(86)90063-1

Bollerslev, T., Chou, R.Y. \& Kroner, K.F., 1992, 'ARCH modeling in finance: A review of theory and empirical evidence', Journal of Econometrics 52(1-2), 5-59. https:// doi.org/10.1016/0304-4076(92)90064-X

Brooks, C., 2008, Introductory econometrics for finance, 2nd edn., Cambridge University Press, New York.

Brzeszczyński, J., Gajdka, J. \& Schabek, T., 2011, 'The role of stock size and trading intensity in the magnitude of the "interval effect" in beta estimation: Empirical evidence from the polish capital market', Emerging Markets Finance and Trade 47(1), 28-49. https://doi.org/10.2753/REE1540-496X470102

Burmeister, E. \& Wall, K.D., 1986, 'The arbitrage pricing theory and macroeconomic factor measures', Financial Review 21(1), 1-21. https://doi. org/10.1111/j.1540-6288.1986.tb01103.x

Cont, R., 2001, 'Empirical properties of asset returns: Stylized facts and statistical issues', Quantitative Finance 1(2), 223-236. https://doi.org/10.1080/713665670 
Czaja, M., Scholz, H. \& Wilkens, M., 2010, 'Interest rate risk rewards in stock returns of financial corporations: Evidence from Germany', European Financial Management 16(1), 124-153. https://doi.org/10.1111/j.1468-036X.2008.00455.x

Dempster, N. \& Artigas, J., 2009, Gold as a tactical hedge and long-term strategic asset, WGC Gold: Report, 2009, World Gold Council, London, pp. 1-12.

Dickey, D.A. \& Fuller, W.A., 1979, 'Distribution of the estimators for autoregressive time series with a unit root', Journal of the American Statistical Association 74(366a) 427-431. https://doi.org/10.1080/01621459.1979.10482531

Engle, R.F., 2001, 'ARCH 101: The use of ARCH/GARCH models in applied econometrics', Journal of Economic Perspectives 15(4), 157-168. https://doi.org/10.1257/ jep.15.4.157

Faff, R. \& Hillier, D., 2004, 'An international investigation of the factors that determine conditional gold betas', Financial Review 39(3), 473-488. https://doi.org/10.1111/ j.0732-8516.2004.00085.x

Fama, E.F., 1965, 'The behaviour of stock-market prices', Journal of Business 38(1), 34-105. https://doi.org/10.1086/294743

Fang, V., Lin, C.T. \& Poon, W., 2007, 'An examination of Australian gold mining firms' exposure over the collapse of gold price in the late 1990s', International Journal of Accounting \& Information Management 15(2), 37-49. https://doi. org/10.1108/18347640710837344

Fei, F. \& Adibe, K., 2010, 'Theories of gold price movements: Common wisdom or myths?', Undergraduate Economic Review 6(1), 1-25.

Gil-Alana, A., Aye, G.C. \& Gupta, R., 2015, Trends and cycles in historical gold and silver prices, Department of Economics Working Paper Series, University of Pretoria, Pretoria, pp. 1-31.

Gilmore, C.G., McManus, G.M., Sharma, R. \& Tezel, A., 2009, 'The dynamics of gold prices, gold mining stock prices and stock market prices comovements', Research in Applied Economics 1(1), E12. https://doi.org/10.5296/rae.v1i1.301

Gujarati, D.N. \& Porter, D.C., 2009, Essentials of econometrics, 4th edn., McGraw-Hill/ Irwin, New York.

Hamilton, J.D., 2010. 'Macroeconomics and ARCH', in Festschrift in Honor of Robert F. Engle, T. Bollerslev, J. Russel \& M. Watson (eds.), Festschrift in Honor of Robert F. Engle, T. Bollerslev, J. Russel \& M. Watson (eds.), Fest
Engle, pp. 79-96, Oxford University Press, Oxford.

Hemavathy, P. \& Gurusamy, S., 2014, 'Impact of gold prices on Indian stock market prices with special reference to global financial crisis - An empirical study', SMS Varanasi $X(1), 1,6-7$

Humphreys, D., 2010, 'The great metals boom: A retrospective', Resources Policy 35(1), 1-13. https://doi.org/10.1016/j.resourpol.2009.07.002

Jaffe, J.F., 1989, 'Gold and gold stocks as investments for institutional portfolios', Financial Analysts Journal 45(2), 53-59. https://doi.org/10.2469/faj.v45.n2.53

Jarque, C.M. \& Bera, A.K., 1987, 'A test for normality of observations and regression residuals', International Statistical Review/Revue Internationale de Statistique 55(2), 163-172. https://doi.org/10.2307/1403192

Jones, E., 2009, 'Output legitimacy and the global financial crisis: Perceptions matter', Journal of Common Market Studies 47(5), 1085-1105. https://doi.org/10.1111/ j.1468-5965.2009.02036.x

Kaneko, T. \& Lee, B.-S., 1995, 'Relative importance of economic factors in the U.S and Japanese stock markets', Journal of the Japanese and International Economies 9(3), 290-307. https://doi.org/10.1006/jjie.1995.1015

Khoury, S.J., 1984, Speculative markets, MacMillan, New York.

Labys, W.C., Achouch, A. \& Terraza, M., 1999, 'Metal prices and the business cycle', Resources Policy 25(1999), 229-238. https://doi.org/10.1016/S0301 4207(99)00030-6

Lawrence, C., 2003, Why is gold different from other assets? An empirical investigation, WGC Gold 2003, World Gold Council, London, pp. 1-26.

Liow, K.H., 2004, 'Time-varying macroeconomic risk and commercial real estate: An asset pricing perspective', Journal of Real Estate Portfolio Management 10(1), 47-57.

Ljung, G.M. \& Box, G.E., 1978, 'On a measure of lack of fit in time series models', Biometrika 65(2), 297-303. https://doi.org/10.1093/biomet/65.2.297

McCown, J.R. \& Zimmerman, J.R., 2006, 'Is gold a zero-beta asset? Analysis of the investment potential of precious metals', viewed 19 May 2015, from http://ssrn. com/abstract $=920496$

McDonald, J.G. \& Solnick, B.H., 1977, 'Valuation and strategy for gold stocks*' The Journal of Portfolio Management 3(3), 29-33. https://doi.org/10.3905/ jpm.1977.408606
McDonald, R.P., 2014, Factor analysis and related methods, Lawrence Erlbaum, Hillsdale, NJ.

McMillan, D.G. \& Ruiz, I., 2009, 'Volatility persistence, long memory and timevarying unconditional mean: Evidence from 10 equity indices', Quarterly Review of Economics and Finance 49(2), 578-595. https://doi.org/10.1016/j. Review of Economic

Nangolo, C. \& Musingwini, C., 2011, 'Empirical correlation of commodity prices', The Journal of The South African Institute of Mining and Metallurgy 111, 459-468.

Narayan, P.K. \& Narayan, S., 2010, Modelling the impact of oil prices on Vietnam's stock prices', Applied Energy 87(1), 356-361. https://doi.org/10.1016/j. apenergy.2009.05.037

Nattrass, N., 1995, 'The crisis in South African gold mining', World Development 23(5), 857-868. https://doi.org/10.1016/0305-750X(95)00007-Y

Nelson, D.B., 1991, 'Conditional heteroskedasticity in asset returns: A new approach', Econometrica: Journal of the Econometric Society 59(2), 347-370. https://doi.org/10.2307/2938260

Newey, W. \& West, K., 1987, 'A simple, positive semi-definite, heteroskedasticity and autocorrelation consistent covariance matrix', Econometrica 55, 703-708. https:// doi.org/10.2307/1913610

Phillips, P.C. \& Perron, P., 1988, 'Testing for a unit root in time series regression', Biometrika 75(2), 335-346. https://doi.org/10.1093/biomet/ 75.2 .335

Ploberger, W. \& Krämer, W., 1992, 'The CUSUM test With OLS residuals', Econometrica 60(2), 271-285. https://doi.org/10.2307/2951597

Poon, S. \& Taylor, S.J., 1991, 'Macroeconomic factors and the UK stock market', Journal of Business Finance \& Accounting 8(5), 619-636. https://doi. org/10.1111/j.1468-5957.1991.tb00229.x

Priestley, R., 1996, 'The arbitrage pricing theory, macroeconomic and financial factors, and expectation generating processes', Journal of Banking \& Finance 20(5), 869-890. https://doi.org/10.1016/0378-4266(95)00035-6

Rock, A., 1988, 'Gold: Protection from calamity but a clunky investment otherwise', Money 17(12), 201-202.

Sadorsky, P. \& Henriques, I., 2001, 'Multifactor risk and the stock returns of Canadian paper and forest products companies', Forest Policy and Economics 3(3-4), 199-208. https://doi.org/10.1016/S1389-9341(01)00064-8

Shafiee, S. \& Topal, E., 2010, 'An overview of global gold market and gold price forecasting', Resources Policy 35(2010), 178-189. https://doi.org/10.1016/j. resourpol.2010.05.004

Smith, V.K. \& Hall, T.W., 1972, 'A comparison of maximum likelihood versus blue estimators', The Review of Economics and Statistics 54(2), 186-190. https://doi. org/10.2307/1926280

Solt, M. \& Swanson, P., 1981, 'On the efficiency of the markets for gold and silver', Journal of Business 54, 453-478. https://doi.org/10.1086/296140

Tufano, P., 1998, 'The determinants of stock price exposure: Financial engineering and the gold mining industry', Journal of Finance 53(3), 1015-1052. https://doi. org/10.1111/0022-1082.00042

Tully, E. \& Lucey, B.M., 2007, 'A power GARCH examination of the gold market', Science Direct Research in International Business and Finance 21, 316-325. https://doi. org/10.1016/j.ribaf.2006.07.001

Twite, G., 2002, 'Gold prices, exchange rates, gold stocks and the gold premium', Australian Journal of Management 72(2), 123-140. https://doi. org/10.1177/031289620202700202

Van Rensburg, P., 1996, 'Macroeconomic identification of the priced APT factors on the Johannesburg Stock Exchange', South African Journal of Business Management 27(4), 104-112.

Vize, R., Coughlan, J., Kennedy, A. \& Ellis-Chadwick, F., 2009, 'Investigating the factors impacting retailers evaluations of web solution providers', viewed 02 February 2017, from http://oro.open.ac.uk/27789/2/11E8793B.pdf

Wurm, L.H. \& Fisicaro, S.A., 2014, 'What residualizing predictors in regression analyses does (and what it does not do)', Journal of Memory and Language 72, 37-48. https://doi.org/10.1016/j.jml.2013.12.003

Xiao, L. \& Aydemir, A., 2007, 'Volatility modeling and forecasting in finance', in J. Knight \& S. Satchell (eds.), Forecasting volatility in the financial markets, 3rd edn., pp. 1-45, Elsevier, Oxford. 